- 研究报告・

\title{
山东东营和烟台潮间带海草床 食物网结构特征
}

\author{
宋 博 1,2 陈琳琳 ${ }^{2}$ 间 朗 ${ }^{2}$ 姜少玉 ${ }^{2}$ 刘春云 $^{2}$ 李秉钧 $1^{*}$ 李宝泉 $2^{*}$ \\ 1 (烟台大学海洋学院, 山东烟台 264003) \\ 2 (中国科学院烟台海岸带研究所海岸带生物学与生物资源保护实验室, 山东烟台 264003)
}

摘要: 为了探明海草床内主要生物类群间的营养关系以及食物网结构, 作者于2018年8月分别在东营黄河口潮间 带和烟台西海岸潮间带海草床采集大型底栖生物样品, 采用 $\delta^{13} \mathrm{C}$ 和 $\delta^{15} \mathrm{~N}$ 稳定同位素方法, 对生物样品的碳、氮同位 素组成进行了测定和分析。结果表明: 东营海草床内生物的 $\delta^{13} \mathrm{C} 、 \delta^{15} \mathrm{~N}$ 值范围分别为 $-21.99 \%$ 至 $-12.13 \%$ 和 $5.23 \% 0-11.05 \%$, 烟台海草床内生物的 $\delta^{13} \mathrm{C} 、 \delta^{15} \mathrm{~N}$ 值范围分别为 $-18.11 \%$ 至 $-14.06 \%$ 和 $6.60 \%-10.22 \%$ 。东营海草床 主要生物的营养级范围为 $2.00-3.85$, 烟台海草床主要生物的营养级范围为 $2.00-3.15$ 。根据 $\delta^{15} \mathrm{~N}$ 值计算所得的营养 级图分析可知两区域海草床内初级消费者主要为滤食性双壳类和多毛类, 次级消费者为植食性或杂食性甲壳类, 肉食性鱼类和腹足类。与近海海域大型底栖生物食物网相比, 海草床内底栖生物的营养级均值普遍较低。

关键词: 稳定同位素; 海草床; 食物网; 营养级; 大型底栖生物

\section{Food web characteristics of seagrass beds in intertidal of Dongying and Yantai, Shandong Province}

\author{
Bo Song ${ }^{1,2}$, Linlin Chen ${ }^{2}$, Lang Yan², Shaoyu Jiang ${ }^{2}$, Chunyun $\mathrm{Liu}^{2}$, Bingjun $\mathrm{Li}^{{ }^{*}}$, Baoquan $\mathrm{Li}^{2 *}$ \\ 1 School of Ocean, Yantai University, Yantai, Shandong 264003 \\ 2 Key Laboratory of Coastal Biology and Bioresource Utilization, Yantai Institute of Coastal Zone Research, Chinese \\ Academy of Sciences, Yantai, Shandong 264003
}

\begin{abstract}
To understand the nutritional relationship among benthic organisms and the food web characteristics in seagrass beds, we collected macrobenthic organisms in intertidal zones of the Yellow River Delta of Dongying and the west coast of Yantai in August 2018. We used $\delta^{13} \mathrm{C}$ and $\delta^{15} \mathrm{~N}$ stable isotopes determine trophic position. The range of organisms isotopic values in the Dongying seagrass bed were $-21.99 \%$ to $-12.13 \%$ for $\delta^{13} \mathrm{C}$ and $5.23 \%$ to $11.05 \%$ for $\delta^{15} \mathrm{~N}$; and $-18.11 \%$ o to $-14.06 \%$ o $\left(\delta^{13} \mathrm{C}\right)$ and $6.60 \%$ o to $10.22 \%\left(\delta^{15} \mathrm{~N}\right)$ in the Yantai seagrass bed. In the Dongying seagrass bed, the trophic level of main organisms ranged from 2.00 to 3.85, while in the Yantai seagrass bed the trophic range was from 2.00 to 3.15 . According to $\delta^{15} \mathrm{~N}$ value calculations, we found that the primary consumers in these two area's seagrass bed were filter feeding bivalves and polychaetes; the secondary consumers were plant-eating or omnivorous crustaceans, carnivorous fish and gastropods. Compared to offshore habitats, the average trophic position of macrobenthic organisms in seagrass beds was relatively low.
\end{abstract}

Key words: stable isotope; seagrass bed; food web; trophic level; macrobenthos

海草床能够为海洋生物提供栖息和庇护场所, 具有较高的生物多样性和生产力, 对海岸带生态系 统发展具有极大的贡献, 是重要的海洋生态系统之
一。近年来由于人类活动的影响, 海草床遭受到不 同程度的破坏，导致海草床面积缩小，裸露区域面 积增大, 海草床生境片断化情况愈加严峻, 使海草

收稿日期: 2019-09-01; 接受日期: 2019-09-25

基金项目: 中国科学院前沿科学重点研究项目(QYZDB-SSW-DQC041)、美丽中国生态文明建设科技工程专项(XDA23050304; XDA23050202)和中国科 学院特别交流项目

* 共同通讯作者 Co-authors for correspondence. E-mail: Li6234307@163.com; bqli@yic.ac.cn 
床内的生物群落面临严重威胁, 由此产生的影响成 为海岸带保护生态学关注的焦点问题之一(许战洲 等, 2009)。大型底栖生物是海草床生态系统的重要 组成部分, 其群落特征和分布情况与海草床的面积 及密集程度有很大关系(Orth et al, 1984; Blanchet et al, 2004)。研究表明可通过海草床生态系统的健康 状况评估其内部大型底栖生物的群落结构特征 (Smith, 1981; Livingstern, 1984)。在广西合浦地区, 随着海草床面积减小，其内主要栖息生物儒艮 (Trichechus dugong)的数量也随之减少, 这也从一 定程度上说明了海草床的破坏对其内部的生物生 活造成威胁(李颖虹等, 2007)。滩涂贝类的人工采收 会对海草床及其内部生物群落结构产生负面影响 (Cabaco et al, 2005; Etxandi et al, 2017); 养殖活动 过程中投喂外源性食物和滥用药物, 导致海草床内 底泥中的氮磷含量明显高于近岸海域的底泥 (吴瑞 和王道儒，2013); 沿海养殖、围网捕鱼、人为污染 等因素导致海草床面积急剧减少, 同时造成海草床 内生物量和生产力降低(黄小平等, 2006); 对潮间 带海草床的连片挖掘, 也使得海草床内大型底栖生 物种类多样性、生物量及栖息密度大大降低(苏志南 等, 2017)。

稳定碳、氮同位素技术能够提供食物网中物质 和能量的传递信息, 且测定速度快、结果准确可靠, 已经广泛应用于水生生态系统食物网结构的构建 (李云凯等, 2014)。通过对生物组织碳氮的测定可以 得到不同生物的摄食食性及其营养等级关系(Lange et al, 2018)。与传统的胃含物分析法相比, 生物组织 的碳氮稳定同位素测定结果能够说明生物在某一 较长时间段内对食物的代谢和吸收情况, 既能表达 生物摄取食物的信息, 也能表达生物对食物的吸收 情况(Kidd et al, 1995)。 $\delta^{13} \mathrm{C}$ 值常被用来反映生物的 食物来源及食物网中碳的流动情况(Guzzo et al, 2011); 而食物网中的氮稳定同位素比值往往会随 着营养层次升高而出现稳定的富集现象(Deniro \& Epstein, 1981), 因此 $\delta^{15} \mathrm{~N}$ 常常被用来确定生物的营 养等级(Carlos et al, 2009)。近年来国内外学者应用 稳定同位素技术对海洋生态系统食物网开展了多 项研究, 如根据南极半岛底栖生物群落的碳氮稳定 同位素比值, 确立了海草床内大型底栖生物的营养 级和同化关系(Kenneth, 2001); 分析明确了比斯开 湾大陆架的底栖生物种类并构建其食物网结构
(Loch et al，2008); 掌握了爱德华王子岛海域的食 物网营养结构(Kaehler et al, 2000)。对于国内的近岸 海域和海湾河口，已经初步建立了黄海和东海海域 生物的食物网营养图谱(蔡德陵等, 2005); 明确了 雷州湾近岸海域主要鱼类的营养级层次(卢伙胜等, 2009); 掌握了长江口及南黄海水域拖网生物的营 养级结构特征(李忠义等, 2010); 研究并绘制了草 海湿地生物的食物链结构(宋正城等, 2019); 在黄 河口潮间带区域，发现大型底栖动物营养级和不同 组织的稳定同位素值存在差异(刘博等, 2019)。综上, 已有的研究多集中于黄渤海近岸海域或南海及各 个海湾、河口等大面积区域，对受到人类活动干扰 明显的潮间带海草床生态系统的食物网营养结构 的研究目前尚未见报道。

本研究利用碳氮稳定同位素技术，分析了东营 黄河口和烟台西海岸潮间带海草床内主要大型底 栖生物的营养级特征，构建了海草床内生物营养级 图谱; 初步建立了海草床内食物网结构, 推测海草 床内生物群落特征的变化趋势, 以期为了解海草床 内生物物质循环和能量流动提供数据支撑, 为海草 床的保护和修复奠定理论基础。

\section{材料与方法}

\section{1 样品的采集与处理}

2018年8月在东营黄河口(37050'59" -37 $57^{\circ} 1^{\prime} 10^{\prime \prime}$ N, $119^{\circ} 6^{\prime} 33^{\prime \prime}-119^{\circ} 6^{\prime} 43^{\prime \prime}$ E) 和烟台西海岸(37 $35^{\prime} 33^{\prime \prime}-$

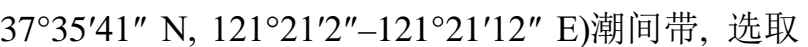
海草床内海草密集区按照三角形设置3个采样点, 采集大型底栖生物样品(图1)。在低潮期海草露出时, 用 $25 \mathrm{~cm} \times 25 \mathrm{~cm} \times 30 \mathrm{~cm}$ 的不锈钢采样框采集海草 及沉积物, 经 $0.5 \mathrm{~mm}$ 孔径的篎网淘洗, 获取的大型 底栖动物样品放入冰盒中带回实验室进行物种鉴 定和解剖取样。实验证明生物肌肉样品的 $\delta^{13} \mathrm{C}$ 和 $\delta^{15} \mathrm{~N}$ 值与生物整体的 $\delta^{13} \mathrm{C}$ 和 $\delta^{15} \mathrm{~N}$ 值相近 ${ }^{(1)}$ ，因此所有 生物样品用超纯水清洗，腹足类取足部肌肉，虾类 取腹部肌肉, 蟹类取螯足肌肉, 双壳类取其闭壳肌， 鱼类取背部肌肉。样品经冷冻干燥 $\left(-80^{\circ} \mathrm{C}\right)$ 恒重后用 玛瑙研钵磨成粉末，过100目篮绢后分成两份，一 份用 $1 \mathrm{~mol} / \mathrm{L}$ 的 $\mathrm{HCl}$ 酸化并离心, 用超纯水洗净消除 无机碳影响，用于碳稳定同位素的测定; 另一份用

(1) Fry B (1977) Stable Carbon Isotope Ratios-A Tool for Tracing Food Chains. MA thesis, Austin University of Texas. 


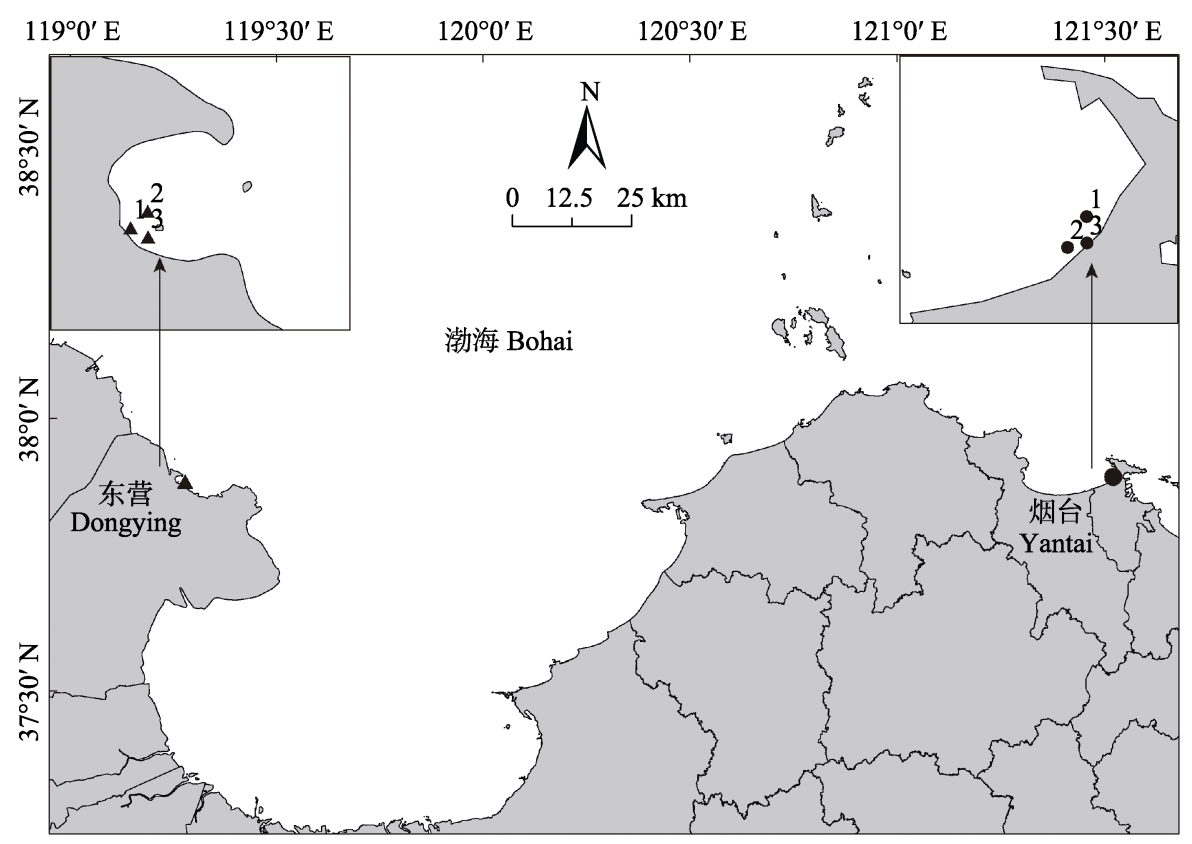

图1 山东东营和烟台潮间带海草床采样点设置

Fig. 1 Sampling sites of intertidal seagrass beds in Dongying and Yantai

于氮稳定同位素测定, 两份样品置于干燥血中用锡 纸杯包样上机测定。

\section{2 肌肉组织中碳氮稳定同位素的测定}

生物样品的 $\delta^{13} \mathrm{C}$ 和 $\delta^{15} \mathrm{~N}$ 稳定同位素比值的测定 方法如下: 每种生物样品取 0.2-0.8 mg, 3个平行样 品上下误差范围不超过 $10 \%$, 用 $4 \mathrm{~mm} \times 6 \mathrm{~mm}$ 的锡 纸杯包样后, 使用MAT253气体稳定同位素质谱仪 (美国Thermo Fisher公司)测定。取3个平行样的均 值。稳定碳氮同位素的计算公式如下:

$$
\delta \mathrm{X}=\left[\left(\mathrm{R}_{\text {样品 }} / \mathrm{R}_{\text {标准 }}\right)-1\right] \times 10^{3}(\%)
$$

式中, $X$ 代表 ${ }^{13} C$ 或 ${ }^{15} \mathrm{~N}, \mathrm{R}$ 为重同位素和轻同位素的 比值 $\left({ }^{13} \mathrm{C} /{ }^{12} \mathrm{C} 、{ }^{15} \mathrm{~N} /{ }^{14} \mathrm{~N}\right)$ 。其中碳稳定同位素的标准 物质为VPDB (Vienna Pee Dee Belemnite), 氮稳定 同位素的标准物质为空气中的 $\mathrm{N}_{2} 。 \delta^{13} \mathrm{C}$ 值分析精度 $<0.2 \%$, $\delta^{15} \mathrm{~N}$ 值分析精度 $<0.4 \%$ 。

\section{3 营养级的计算公式}

海草床内生物的营养级计算公式(Cabana \& Rasmussen, 1986)如下:

$$
\mathrm{TL}=\left(\delta^{15} \mathrm{~N}_{\text {消费者 }}-\delta^{15} \mathrm{~N}_{\text {基准生物 }}\right) \mathrm{TEF}+\lambda
$$

式中, TL表示所计算生物的营养级水平, $\delta^{15} \mathrm{~N}_{\text {消费者为 }}$

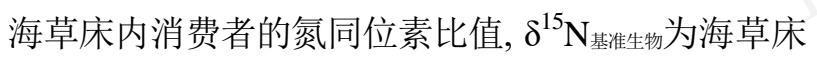
内基准生物的氮同位素比值, 本研究选取两区域的 常见种青蛤(Cyclina sinensis)和异白樱蛤(Macoma incongrua)作为基准生物。TEF为相邻营养级的富集
程度, 参考国外学者应用稳定同位素计算营养级的 研究结果(Post, 2002), 本研究也取其值为3.4\%。 $\lambda$ 为基准生物的营养级, 由于两种双壳类基准生物都 为滤食性的初级消费者, 此处 $\lambda$ 取 2 。

\section{4 数据处理}

根据生物种类的碳氮稳定同位素值，使用 Origin 9.1绘图。采用Primer 6.0 对 $\delta^{13} \mathrm{C}$ 和 $\delta^{15} \mathrm{~N}$ 比值数 据先进行平方根转换, 再进行Bray-Curtis相似性处 理, 然后对两地海草床内主要生物类群的食性进行 聚类分析。

\section{结果}

\section{1 生物碳氮稳定同位素值}

本研究在东营黄河口和烟台西海岸海草床生 境内共计采集大型底栖生物 17 种, 其中腹足类 5 种, 甲壳类3种，双壳类4种，多毛类2种，鱼类3种。

东营黄河口海草床内不同生物的 $\delta^{13} \mathrm{C}$ 值差距较 明显, 其范围为 $-21.99 \%$ 至 $-12.13 \%$, 平均为 $-16.46 \%$ o $\pm 0.27 \%$; $\delta^{15} \mathrm{~N}$ 值范围为 $5.23 \%$ - $11.05 \%$, 平均为 $8.13 \% \circ \pm 0.19 \% 。$ 。 $\delta^{13} \mathrm{C}$ 值最大的为肉食性甲壳 类葛氏长臂虾(Palaemon gravieri) $(-12.13 \%$ 土 $0.12 \%$ ), 最小的为肉食性鱼类日本海马(Hippocampus mohnikei) $\left(-21.99 \%\right.$ $\pm 0.52 \%$ ) $; \delta^{15} \mathrm{~N}$ 值最大的为肉食 性鱼类矛尾刺虾虎鱼(Chaeturichthys stigmatias) 
表1 东营黄河口和烟台西海岸海草床内主要生物的 $\delta^{13} \mathbf{C}$ 和 $\delta^{15} \mathrm{~N}$ 稳定同位素值

Table $1 \quad \delta^{13} \mathrm{C}$ and $\delta^{15} \mathrm{~N}$ values of major organisms collected within Dongying and Yantai seagrass beds

\begin{tabular}{|c|c|c|c|}
\hline 物种 Species & 样本数 Samples & $\delta^{13} \mathrm{C}(\%)($ Mean $\pm \mathrm{SD})$ & $\delta^{15} \mathrm{~N}(\%)($ Mean $\pm \mathrm{SD})$ \\
\hline \multicolumn{4}{|l|}{ 东营 Dongying } \\
\hline \multicolumn{4}{|l|}{ 腹足类 Gastropods } \\
\hline 托氏昌螺 Umbonium thomasi & 67 & $-14.13 \pm 0.10$ & $8.66 \pm 0.09$ \\
\hline 微黄镰玉螺 Euspira gilva & 2 & $-15.54 \pm 0.28$ & $8.77 \pm 0.02$ \\
\hline 古氏滩栖螺 Batillaria cumingi & 43 & $-12.85 \pm 0.39$ & $7.42 \pm 0.25$ \\
\hline \multicolumn{4}{|l|}{ 甲壳类 Crustacea } \\
\hline 日本大眼蟹 Macrophthalmus japonicus & 4 & $-14.18 \pm 0.14$ & $6.49 \pm 0.33$ \\
\hline 葛氏长臂虾 Palaemon gravieri & 5 & $-12.13 \pm 0.12$ & $7.88 \pm 0.18$ \\
\hline \multicolumn{4}{|l|}{ 双壳类 Bivalve } \\
\hline 青蛤 Cyclina sinensis & 8 & $-20.18 \pm 0.08$ & $5.23 \pm 0.23$ \\
\hline 四角蛤蜊 Mactra quadrangularis & 8 & $-19.90 \pm 0.32$ & $6.50 \pm 0.06$ \\
\hline \multicolumn{4}{|l|}{ 鱼类 Fish } \\
\hline 日本海马 Hippocampus mohnikei & 2 & $-21.99 \pm 0.52$ & $9.87 \pm 0.30$ \\
\hline 鲻鱼 Mugil cephalus & 3 & $-16.08 \pm 0.62$ & $9.46 \pm 0.24$ \\
\hline 矛尾刺虾虎鱼 Chaeturichthys stigmatias & 3 & $-17.59 \pm 0.09$ & $11.05 \pm 0.15$ \\
\hline \multicolumn{4}{|l|}{ 烟台 Yantai } \\
\hline \multicolumn{4}{|l|}{ 腹足类 Gastropods } \\
\hline 宽带薄梯螺 Epitonium latifasciatum & 8 & $-14.62 \pm 0.22$ & $7.76 \pm 0.14$ \\
\hline 扁玉螺 Glossaulax didyma & 2 & $-17.41 \pm 0.09$ & $8.19 \pm 0.77$ \\
\hline 古氏滩栖螺 Batillaria cumingi & 26 & $-14.57 \pm 0.29$ & $8.00 \pm 0.09$ \\
\hline \multicolumn{4}{|l|}{ 甲壳类 Crustacea } \\
\hline 线毛近方蟹 Hemigrapsus penicillatus & 3 & $-14.75 \pm 0.07$ & $10.22 \pm 0.13$ \\
\hline 日本大眼蟹 Macrophthalmus japonicus & 3 & $-14.06 \pm 0.16$ & $10.03 \pm 0.25$ \\
\hline \multicolumn{4}{|l|}{ 双壳类 Bivalve } \\
\hline 菲律宾蛤仔 Ruditapes philippinarum & 19 & $-18.11 \pm 0.09$ & $7.11 \pm 0.64$ \\
\hline 异白樱蛤 Macoma incongrua & 16 & $-14.64 \pm 0.13$ & $6.60 \pm 0.31$ \\
\hline \multicolumn{4}{|l|}{ 多毛类 Polychaeta } \\
\hline 日本刺沙蚕 Hediste japonica & 6 & $-17.35 \pm 0.21$ & $7.66 \pm 0.22$ \\
\hline 红色叶蛰虫 Amphitrite rubra & 8 & $-16.62 \pm 0.04$ & $8.94 \pm 0.29$ \\
\hline
\end{tabular}

(11.05\% $\pm 0.15 \%)$, 最小的为滤食性双壳类青蛤 (5.23\%o $\pm 0.23 \%$ o)(表1)。

烟台西海岸海草床内不同生物的 $\delta^{13} \mathrm{C}$ 值也有较 大差异, 其范围为 $-18.11 \%$ 至 $-14.06 \%$, 平均值为 $-15.79 \%$ o $\pm 0.14 \%$; $\delta^{15} \mathrm{~N}$ 值范围为 $6.60 \%$ - $10.22 \%$, 平均值为 $8.28 \%$ o $\pm 0.32 \%$ 。其中 $\delta^{13} \mathrm{C}$ 值最大的为植食 性甲壳类日本大眼蟹 (Macrophthalmus japonicus) $(-14.06 \%$ o $\pm 0.16 \%)$, 最小的为滤食性双壳类菲律 宾蛤仔(Ruditapes philippinarum)(-18.11\%o $\pm 0.09 \%$ ); $\delta^{15} \mathrm{~N}$ 值最大的为植食性甲壳类线毛近方蟹 $(\mathrm{Hemi}-$ grapsus penicillatus)(10.22\%o $\pm 0.13 \%$ ), 最小的为滤 食性双壳类异白樱蛤 $(6.60 \%$ o $\pm 0.31 \%$ o 。

两区域都含有日本大眼蟹和古氏滩栖螺
(Batillaria cumingi), 且烟台西海岸海草床内两种生 物的 $\delta^{15} \mathrm{~N}$ 值大于东营黄河口(表1)。

\section{2 生物营养级}

两区域生物组成不同, 呈现出不同的营养级图 谱(图2)。

东营黄河口海草床内消费者营养级的范围为 2.00 (青蛤) -3.85 (矛尾刺虾虎鱼), 营养层次的长度 为 2 级, 其中腹足类为 $2.70-3.09$, 甲壳类为 2.40-2.84, 双壳类为 $2.00-2.40$, 鱼类为 3.34-3.85; 烟台西海岸海草床内消费者营养级的范围为 2.00 (异白樱蛤) -3.15 (线毛近方蟹), 营养层次长度为 2 级, 其中腹足类为2.37-2.51, 甲壳类为3.09-3.15, 双壳 类为2.00-2.16, 多毛类为2.34-2.74。两区域中活动 

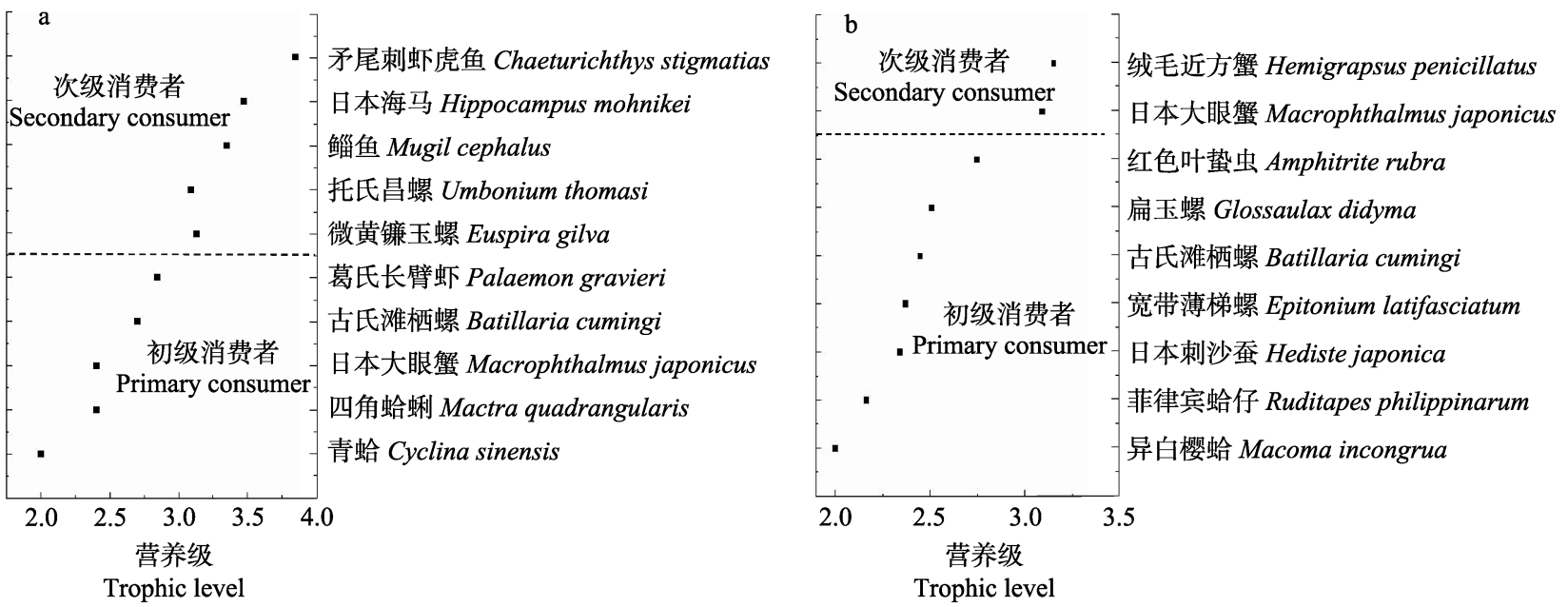

图2 东营(a)和烟台(b)海草床内主要生物营养级

Fig. 2 Trophic level of organisms in seagrass beds in Dongying (a) and Yantai (b)

范围较小的双壳类和腹足类营养级较低, 在海草床 内占据的营养位置较低; 而活动范围较大的甲壳类 和鱼类营养级较高, 在海草床内占据的营养位置也 较高。腹足类、双壳类在黄河口区域的营养层次都 高于在西海岸区域。

\section{3 海草床内生物食性和营养级}

聚类分析结果表明(图3), 两区域潮间带海草 床生态系统内的消费者按照 $94 \%$ 的相似性水平大体 可分为两个营养群组: 东营黄河口区域的第1群组 为滤食性双壳类, 由青蛤和四角蛤蜊 (Mactra quadrangularis)组成; 第二群组又以超过 $96 \%$ 的相似性 水平分为 $2 \mathrm{a}$ 和 $2 \mathrm{~b}$ 群组, 其中 $2 \mathrm{a}$ 群组为植食性和杂食 性甲壳类, 由日本大眼蟹和日本海马组成; $2 \mathrm{~b}$ 群组 为肉食性腹足类和鱼类, 由微黄镰玉螺 (Euspira gilva)、鲻鱼(Mugil cephalus)、矛尾刺虾虎鱼组成。

烟台西海岸区域第1群组为植食性甲壳类, 由线 毛近方蟹和日本大眼蟹组成; 第二群组也以 $95 \%$ 的 相似性水平分为 $2 \mathrm{a}$ 和 $2 \mathrm{~b}$ 群组, 其中 $2 \mathrm{a}$ 群组为碎屑食 性腹足类和多毛类, 由古氏滩栖螺、宽带薄梯螺 (Epitonium latifasciatum)、红色叶蛰虫(Amphitrite $r u b r a)$ 组成; $2 b$ 群组为滤食性双壳类及多毛类, 由菲 律宾蛤仔和日本刺沙䖯(Hediste japonica)等代表生 物组成。

\section{3 讨论}

\section{1 海草床内生物碳氮稳定同位素值分析}

东营黄河口和烟台西海岸海草床内生物样品
的 $\delta^{13} \mathrm{C}$ 均值范围分别为 $-21.99 \%$ 至 $-12.13 \%$ 和 $-18.11 \%$ 至 $-14.06 \%$, 相邻营养级的物种之间 $\delta^{13} \mathrm{C}$ 值相近且生态位重叠面积较大，说明海草床内食物 网结构相较于浅海海域简单且各生物层次的食源 相近。 $\delta^{15} \mathrm{~N}$ 均值范围分别为 $5.23 \%$ - $11.05 \%$ 和 $6.60 \% 0-10.22 \%$, 两地 $\delta^{15} \mathrm{~N}$ 值相较于浅海海域范围 和跨度均较低。黄河口海草床内生物的 $\delta^{13} \mathrm{C}$ 值及 $\delta^{15} \mathrm{~N}$ 值范围和跨度均小于渤海湾(万神等, 2005)和 辽东湾(孙明等, 2013)的主要渔业生物, 可能原因是 黄河口和其他两地生境差异较大, 其内栖息的生物 类群也存在较大差异, 黄河口海草床面积范围小, 其内栖息的生物相对较少, 生物多样性较低。例如, 矛尾刺虾虎鱼的 $\delta^{15} \mathrm{~N}$ 值在黄河口海草床所有生物中 为最高(11.05\% $\pm 0.15 \%$ ), 但在渤海湾(万神等, 2005)和辽东湾(孙明等, 2013)中并不是最高, 不处于 食物链顶端。

黄河口海草床内生物碳氮同位素比值差异不 显著 $(P>0.05)$, 说明各生物类群食源组成简单导致 群落营养结构简单化(纪炜炜等, 2015), 即摄食特化 程度较高，使得碳氮稳定同位素比值范围跨度较 小。同时本研究还发现，两地海草床内生物氮稳定 同位素比值相对于近海海域较低，其原因可能是人 类活动对近海海域陆源物质的排放导致其食物网 中 $\delta^{15} \mathrm{~N}$ 的值偏高(Nixon et al, 2007)。而海草床位于 潮间带, 工厂排污管道无法安装至此，因此受到陆 源物质输入影响较小, $\delta^{15} \mathrm{~N}$ 值较低。与烟台西海岸相 比，东营黄河口海草床内生物的 $\delta^{13} \mathrm{C}$ 值及 $\delta^{15} \mathrm{~N}$ 值范 
a

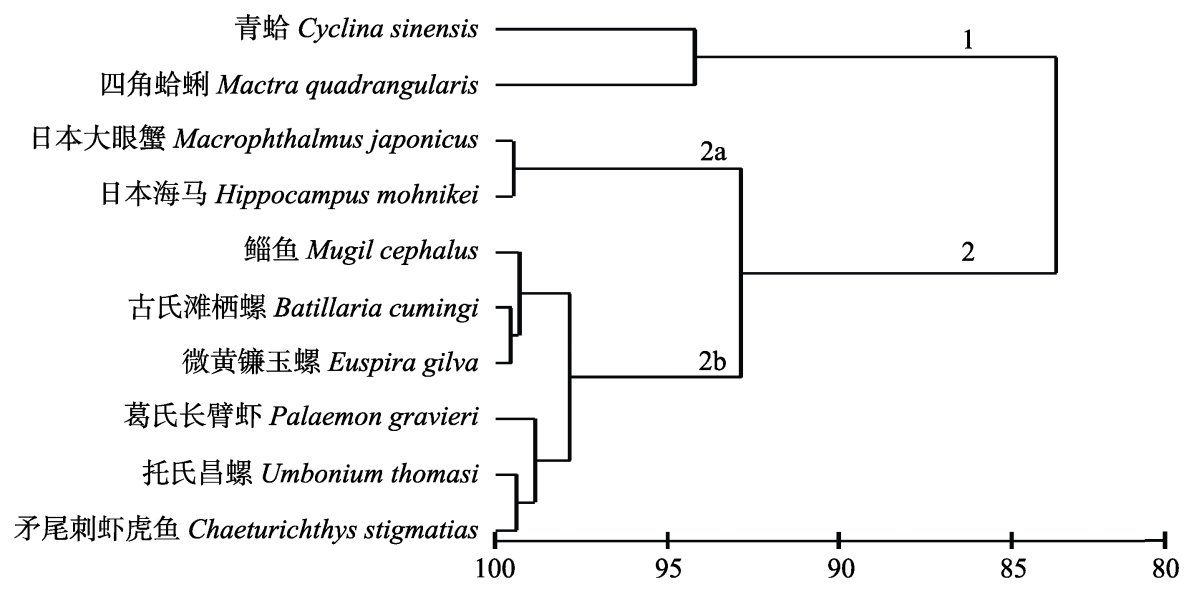

b

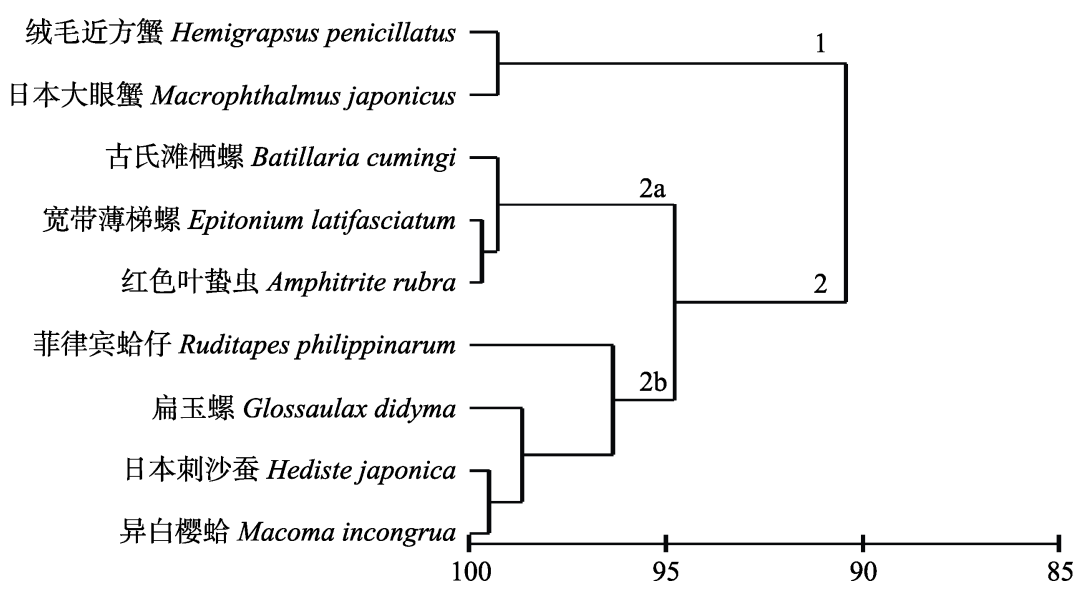

图3 东营(a)和烟台(b)海草床内主要生物 $\delta^{13} C$ 和 $\delta^{15} N$ 比值聚类分析

Fig. 3 Cluster analysis of $\delta^{13} \mathrm{C}$ and $\delta^{15} \mathrm{~N}$ values of major organisms in Dongying (a) and Yantai (b) seagrass beds

围和跨度均较高。结合现场采集情况, 除两地生态 环境和初级生产力水平差异外, 可能原因是由于东 营黄河口采样地偏远, 且位于保护区内, 人类活动 影响相对较少, 海草床健康状况较好, 呈连片分布; 而烟台西海岸潮间带赶潮者和游客较多, 海草床生 境破坏更为严重, 导致其内生物摄食特化程度高, 碳氮稳定同位素比值范围和跨度较小。

\section{2 海草床内生物营养级分析}

基线生物的正确选取是保证生物营养级计算 准确的关键因素(Hoekman et al, 2012)。选取时主要 考虑以下两点: (1)食性稳定、生活周期长; (2)在海草 床内活动半径小且分布较密集, 具有一定的代表 性。选取方法依据对象动物的栖息生境而定, 在河 口和海湾、浅海区域和深海有较大差异(贡艺等, 2017)。由于海草床区域之前开展的食物网研究较少, 未有相应的选取依据可供参考, 考虑到潮间带海草 床与河口和海湾生态环境存在一定的相似性, 故本
研究参考海洋生态系统中稳定同位素基线选取的 研究方法, 在东营黄河口选取长期栖息于海草床内 的初级消费者青蛤为基准生物，其闭壳肌的氮同位 素比值为5.23\% ; 在烟台西海岸选取异白樱蛤为基 准生物, 其闭壳肌的氮同位素比值为6.60\%。

不同海域内生物的营养级计算结果不仅受基 线生物的选取、相邻营养级富集程度(TEF)等因素 的影响，同时还受海域生物个体大小及摄食同化率 等多方面的影响(孙明等, 2017)。例如辽东湾海哲的 食性和营养级与其伞径的大小有关，伞径大的营养 级较高。因此比较生物在不同海域营养级的差异时, 应尽量保证上述变量相同。与枸杞岛(蒋日进等, 2014)和大连近岸海域(王䒜等, 2017)的生物营养级 层次长度 4 相比, 本研究两地的生物营养级层次长 度分别为 1.15 和 1.85 , 远低于 4 。同时, 本研究各个 层级消费者的营养级均值低于之前已有的对近岸 海域研究的生物营养级均值, 如本研究中初级消费 
者四角蛤蜊的营养级为 2.4 , 低于鸭绿江近岸海域 春季四角蛤蜊的营养级2.78(田甲申等, 2018); 扁玉 螺 (Glossaulax didyma) 和葛氏长臂虾的营养级分别 为2.51和 2.84, 明显低于海州湾(3.1, 3.1)(张硕等, 2016); 鲻鱼的营养级为3.34, 低于枸杞岛近岸海域 的4.01。本研究的富集因子与大连近岸海域和枸杞 岛的取值相同(3.4\%o)，因此造成上述差异的原因可 能与基线生物的选取和研究区域生态系统差异有 关。本研究选取的基线生物值(5.23\% 、6.60\%o)高于 大连近岸海域的基准生物栉孔扇贝 (Chlamys farreri)(5.84\%) 和枸杞岛的浮游生物 (4.9\%o), 造成 营养级计算结果稍低。同时, 由于人类采集破坏和 海草床生境片断化, 致使各个层次的消费者尤其是 鲻鱼和矛尾刺虾虎鱼等高级消费者摄食质量差, 生 物体内碳氮元素的同化率较低(Madurell et al, 2008), 导致生物营养级层次长度较短和营养级较低。

\section{3 海草床内生物食性和营养级关系}

东营和烟台潮间带海草床生态系统内生物食 性聚类分析结果与胶州湾(麻秋云等, 2015)和大凌 河鸭绿江(田甲申等, 2018)大致相同, 但本研究海草 床内的两个生物群组中生物构成较简单。其中第一 营养群组内生物碳氮稳定同位素比值较低, 组内生 物为处于低营养级的初级消费者, 活动范围较小, 食物来源范围较窄，主要食性为滤食性和碎屑食性; 第二营养群组内生物碳氮稳定同位素比值较高, 组 内生物属于次级和高级消费者, 活动范围较大, 食 物范围较宽泛, 主要食性为植食性和肉食性。将食 性和营养级结合后我们发现, 海草床内生物食性对 生物所处的营养层次也有较大影响。营养级排序为: 滤食性和碎屑食性的双壳类和多毛类 < 植食性和 杂食性的甲壳类 < 肉食性的腹足类和鱼类, 即摄 食层次越高, 营养级越高。这与前人对其他近岸海 域和河流湖泊的研究结果一致, 如间光松等(2016) 对长江口主要渔业生物的研究中发现, 毛蚶(Scapharca subcrenata)和锯缘青蟹(Scylla serrata)等活动 范围较小, 滤食性和植食性的消费者在长江口生态 系统中属于初级消费者, 而拉氏狼牙虾虎鱼(Tuenioides rubicundus)和尧嘴鲌(Erythroculter ilishaeformis)等活动范围较大，肉食性的消费者则属于高 级消费者, 能够摄食低营养级的消费者并同化获取 能量。对地中海西北部海域(Nararro et al, 2011)内生 物食物网的研究也发现, 欧洲沙丁鱼 (Sardina pilchardus)的营养级为2.97, 相对较低, 其主要摄食 藻类和桡足类等, 食性为滤食性和碎屑食性(王军 等，1986), 在海域内属于次级消费者; 而宽吻海豚 (Tursiops truncatus)和蓝鯺金枪鱼(Thunnus thynnus) 的营养级分别为 4.51 和 4.42 , 相对较高, 其食性为肉 食性，属于高级消费者。

本研究分别对山东地区的两处潮间带海草床 内的大型底栖生物进行了营养级和食性分析，初步 构建山东东营和烟台地区潮间带海草床内大型底 栖生物营养结构图谱, 预测海草床由于生境片断化 导致其内生物多样性降低和营养级降低的变化趋 势。两处海草床由于人类活动影响的不同，在食物 网和营养级方面也呈现一定程度的差异，体现出人 类活动对海草床生态系统的干扰。

\section{参考文献}

Blanchet H, Montaudouin X, Lucas A, Chardy P (2004) Heterogeneity of macrozoobenthic assemblages within a Zostera noltii seagrass bed: Diversity, abundance biomass and structuring factors. Estuarine, Coastal and Shelf Science, 61, 111-123.

Cabaco S, Alexander A, Santos R (2005) Population level effects of clam havesting on the seagrass Zostera noltii. Marine Ecology Progress Series, 298, 123-129.

Cabana G, Rasmussen JB (1986) Comparison of aquatic food chains using nitrogen isotopes. Australian Journal of Ecology, 11, 121-134.

Cai DL, Li HY, Tang QS, Sun Y (2005) Establishment of continuous nutrient spectra of food webs in the Yellow Sea and East China Sea ecosystem: Results from stable isotope methods of carbon and nitrogen. Science China: Life Sciences, 35, 123-130. (in Chinese) [蔡德陵, 李红燕, 唐启升, 孙耀 (2005) 黄东海生态系统食物网连续营养谱的建立: 来自碳氮稳定同位素方法的结果. 中国科学: 生命科学, 35, 123-130.]

del Rio CM, Wolf N, Carleton SA, Gannes Z (2009) Isotopic ecology ten years after a call for more laboratory experiments. Biological Reviews of the Cambridge Philosophical Society, 84, 91-111.

Deniro MJ, Epstein S (1981) Influence of diet on the distribution of nitrogen isotopes in animals. Geochimica et Cosmochimica Acta, 45, 341-351.

Etxandi JM, Valle M, Borja A (2017) Effect of trampling and digging from shellfishing on Zostera noltii intertidal seagrass bed. Scientia Marina, 81, 121-128.

Gong Y, Chen L, Li YK (2017) Selection of isotopic baselines in marine ecosystems. Chinese Journal of Applied Ecology, 28, 2399-2404. (in Chinese with English abstract) [贡艺, 陈玲, 李云凯 (2017) 海洋生态系统稳定同位素基线的 
选取. 应用生态学报, 28, 2399-2404.]

Guzzo MM, Haffner GD, Sorge S, Rush SA, Fisk AT (2011) Spatial and temporal variabilities of $\delta^{13} \mathrm{C}$ and $\delta^{15} \mathrm{~N}$ within lower trophic levels of a large lake: Implications for estimating trophic relationships of consumers. Hydrobiologia, 675, 41-53.

Hoekman D, Bartrons M, Gratton C (2012) Ecosystem linkages revealed by experimental lake-derived isotope signal in heathland food webs. Oecologia, 170, 735-745.

Huang XP, Huang LM, Li YH, Xu ZZ, Fang JW, Huang DJ, Han QY, Huang H, Tan YH, Liu S (2006) The main seagrass beds in the coastal areas of South China and their habitat threats. Chinese Science Bulletin, 51, 114-119. (in Chinese) [黄小平, 黄良民, 李颖虹, 许战洲, 方静威, 黄 道建, 韩秋影, 黄晖, 谭烨辉, 刘胜 (2006) 华南沿海主 要海草床及其生境威胁. 科学通报, 51, 114-119.]

Ji WW, Li SF, Chen XZ, Ruan W, Zhou J (2015) Variation in trophic structure of nekton organisms from the northern East China Sea and adjacent waters based on stable isotope values. Marine Fisheries, 37, 494-500. (in Chinese with English abstract) [纪炜炜, 李圣法, 陈雪忠, 阮雯, 周进 (2015) 基于稳定同位素方法的东海北部及其邻近水域主 要游泳动物营养结构变化. 海洋渔业, 37, 494-500.]

Jiang RJ, Zhang SY, Wang K, Zhou XJ, Zhao J (2014) Stable isotope analysis of the offshore food web of Gouqi Island. Chinese Journal of Ecology, 33, 930-938. (in Chinese with English abstract) [蒋日进, 章守宇, 王凯, 周曦杰, 赵静 (2014) 枸杞岛近岸海域食物网的稳定同位素分析. 生态 学杂志, 33, 930-938.]

Kaehler S, Pakhomov EA, McQuaid CD (2000) Trophic structure of the marine food web at the Prince Edward Islands (southern ocean) determined by $\delta^{13} \mathrm{C}$ and $\delta^{15} \mathrm{~N}$ analysis. Marine Ecology Progress Series, 208, 13-20.

Kenneth HD (2001) $\delta^{15} \mathrm{~N}$ and $\delta^{13} \mathrm{C}$ measurements of Antarctic Peninsula fauna: Trophic relationships and assimilation of benthic seaweeds. American Zoologist, 41, 99-112.

Kidd KA, Schindler DW, Hesslein RH, Muir DCG (1995) Correlation between stable nitrogen isotope ratios and concentrations of organochlorines in biota from a freshwater food web. The Science of the Total Environment, 160, 381-390.

Lange G, Haynert K, Dinter T, Scheu S, Kroncke I (2018) Adaptation of benthic invertebrates to food sources along marine-terrestrial boundaries as indicated by carbon and nitrogen stable isotopes. Journal of Sea Research, 131, 12-21.

Li YH, Huang XP, Xu ZZ, Huang LM (2007) Threat and protection measurement of Hepu seagrass beds in Guangxi. Marine Environmental Science, 26, 586-590. (in Chinese with English abstract) [李颖虹, 黄小平, 许战洲, 黄良民 (2007) 广西合浦海草床面临的威胁与保护对策. 海洋环 境科学, 26, 586-590.]

Li YK, Gong Y, Chen XJ (2014) Applications of stable isotope analysis in the trophic ecology studies of cephalopods. Chinese Journal of Applied Ecology, 25, 1541-1546. (in
Chinese with English abstract) [李云凯, 贡艺, 陈新军 (2014) 稳定同位素技术在头足类摄食生态学研究中的应 用. 应用生态学报, 25, 1541-1546.]

Li ZY, Zuo T, Dai FQ, Jin XS (2010) The nutritive grades of spring trawl catches in Yangtze estuary and South Yellow Sea were studied by using stable isotope technique. Journal of Fishery Sciences of China, 17, 103-109. (in Chinese with English abstract) [李忠义, 左涛, 戴芳群, 金显仕 (2010) 运用稳定同位素技术研究长江口及南黄海水域春季拖网 渔获物的营养级. 中国水产科学, 17, 103-109.]

Liu B, Chen LL, Li BQ, Hou XY, Feng GH, Li XW, Li BJ, Wang YJ (2019) Study on the difference of carbon and nitrogen stable isotope ratio between macrobenthic tissues in intertidal zone. Acta Oceanologica Sinica, 41, 74-82. (in Chinese with English abstract) [刘博, 陈琳琳, 李宝泉, 侯 西勇, 冯光海, 李晓炜, 李秉钧, 王玉珏 (2019) 碳氮稳 定同位素比值在潮间带大型底栖动物组织间差异性研究. 海洋学报, 41, 74-82.]

Livingstern RJ (1984) The relationship of physical factors and biological response in coastal seagrass meadows. Estuaries, 7, 377-390.

Loch FL, Hily C, Grall J (2008) Benthic community and food web structure on the continental shelf of the Bay of Biscay (North Eastern Atlantic) revealed by stable isotopes analysis. Journal of Marine Systems, 72, 17-34.

Lu HS, Ou F, Yan YR, Zhang JX (2009) Study on nutrient grades of main fishes in Leizhou Bay by nitrogen stable isotope technique. Acta Oceanologica Sinica, 31, 167-174. (in Chinese with English abstract) [卢伙胜, 欧帆, 颜云榕, 张军晓 (2009) 应用氮稳定同位素技术对雷州湾海域主 要鱼类营养级的研究. 海洋学报, 31, 167-174.]

Ma QY, Han DY, Liu H, Xue Y, Ji YP, Ren YP (2015) Construction of a continuous trophic spectrum for the food web in Jiaozhou Bay using stable isotope analyses. Acta Ecologica Sinica, 35, 7207-7218. (in Chinese with English abstract) [麻秋云, 韩东燕, 刘贺, 薛荣, 纪毓鹏, 任一平 (2015) 应用稳定同位素技术构建胶州湾食物网的连续营 养谱. 生态学报, 35, 7207-7218.]

Madurell T, Fanelli E, Cartes JE (2008) Isotopic composition of carbon and nitrogen of suprabenthic fauna in the NW Balearic Islands (western Mediterranean). Journal of Marine Systems, 71, 336-345.

Nararro J, Coll M, Louzao M, Palomera I, Delgado A, Forero MG (2011) Comparison of ecosystem modelling and isotopic approach as ecological tools to investigate food webs in the NW Mediterranean Sea. Journal of Experimental Marine Biology and Ecology, 401, 97-104.

Nixon SW, Buckley BA, Granger SL, Entsua M, Ansa O, White MJ, McKinney RA, Mensah E (2007) Anthropogenic enrichment and nutrients in some tropical lagoons of Ghana, West Africa. Ecological Applications, 17, S144-S164.

Orth RJ, Heck KL, Montfrans J (1984) Faunal communities in seagrass beds: A review of the influence of plant structure 
and prey characteristics on predator-prey relationships. Estuaries, 7, 339-350.

Post DM (2002) Using stable isotopes to estimate trophic position: Models, methods and assumptions. Ecology, 83, 703-718.

Smith SV (1981) Marine macrophytes as a global carbon sink. Science, 211, 838-840.

Song ZC, Zeng LX, He TR, Li ZJ (2019) Stable carbon and nitrogen isotope characteristics and structure of the food chain in Lake Caohai. Chinese Journal of Ecology, 38, 689-695. (in Chinese with English abstract) [宋正城, 曾玲 霞, 何天荣, 李振吉 (2019) 草海湿地食物链稳定碳氮同 位素特征与食物链结构. 生态学杂志, 38, 689-695.]

Su ZN, Qiu GL, Fan HQ, Wei MQ, Tan SY, Li M (2017) Ecological effects of physical disturbance on seagrass community and associated macrobenthos. Guangxi Science, 24, 474-482. (in Chinese with English abstract) [苏志南, 邱广龙, 范航清, 韦梅球, 谈思泳, 李梦 (2017) 人为物 理干扰对海草群落及大型底栖动物的生态影响. 广西科 学, 24, 474-482.]

Sun M, Liu XZ, Li YP, Dong J (2013) Trophic level analysis of key species in Liaodong Bay using stable nitrogen isotopes. Journal of Fishery Science of China, 20, 189-197. (in Chinese with English abstract) [孙明, 刘修泽, 李轶平, 董 婧 (2013) 应用氮稳定同位素技术研究辽东湾海域主要 渔业生物的营养级. 中国水产科学, 20, 189-197.]

Sun M, Wang B, Li YL, Wang AY, Dong J, Ma TY, Ban YL (2017) Feeding habitats and trophic levels of Rhopilema esculentum Kishinouye in Liaodong Bay based on analyzing carbon and nitrogen stable isotopes. Chinese Journal of Applied Ecology, 27, 1103-1108. (in Chinese with English abstract) [孙明, 王彬, 李玉龙, 王爱勇, 董婧, 麻天宇, 班艳丽 (2017) 基于碳氮稳定同位素技术研究辽东湾海 哲的食性和营养级. 应用生态学报, 27, 1103-1108.]

Tian JS, Li DH, Wang B, Zhou ZC, Lu ZC, You GR, Wu YC (2018) Assessment of the trophic level of main fishery species in coastal waters of Daling River and Yalu River based on stable isotope technique. Chinese Journal of Ecology, 37, 1181-1186. (in Chinese with English abstract) [田甲申, 李多慧, 王摆, 周遵春, 鹿志创, 尤广然, 吴英 超 (2018) 运用稳定同位素技术研究大凌河、鸭绿江近岸 海域春季主要生物种类的营养级. 生态学杂志, 37, 1181-1186.]

Wan Y, Hu JY, An LH, An W, Yang M, Ito M, Hattori S, Tao S (2005) Using stable nitrogen and carbon isotopes to analyze the nutritive levels of major species in the food network in Bohai bay. Chinese Science Bulletin, 50, 708-712. (in Chinese) [万祎, 胡建英, 安立会, 安伟, 杨 敏, 伊藤光明, 服部达也, 陶澍 (2005) 利用稳定氮和碳 同位素分析渤海湾食物网主要生物种的营养层次. 科学 通报, 50, 708-712.]

Wang J, Qiu SY (1986) On the feeding habit of Sardingella aurita in south Fujian-east Guangdong coastal waters. Taiwan Strait, 5, 86-93. (in Chinese with English abstract) [王军, 丘书院 (1986) 闽南粤东近海金色小沙丁鱼的食 性. 台湾海峡, 5, 86-93.]

Wang L, Du SC, Yang TY, Chang YQ (2017) Using stable isotopes to evaluate food web structure in Dalian coastal water. Chinese Journal of Ecology, 36, 1452-1457. (in Chinese with English abstract) [王荤, 杜双成, 杨婷越, 常 亚青 (2017) 应用稳定同位素技术评价大连近岸海域食 物网营养结构. 生态学杂志, 36, 1452-1457.]

Wu R, Wang DR (2013) The present situation of seagrass bed and ecosystem restoration and reconstruction in Hainan Province. Marine Development and Management, (6), 69-72. (in Chinese) [吴瑞, 王道儒 (2013) 海南省海草床现状和 生态系统修复与重建. 海洋开发与管理, (6), 69-72.

Xu ZZ, Luo Y, Zhu AJ, Cai WX (2009) Degradation and restoration of seagrass bed ecosystem. Chinese Journal of Ecology, 28, 2613-2618. (in Chinese) [许战洲, 罗勇, 朱艾 嘉, 蔡伟叙 (2009) 海草床生态系统的退化及其恢复. 生 态学杂志, 28, 2613-2618.]

Yan GS, Zhang T, Zhao F, Wang SK, Yang G, Wang S, Zhang LZ (2016) A study on trophic level of the major fishery species from the Yangtze Estuary based on stable isotope technology. Chinese Journal of Ecology, 35, 3131-3136. (in Chinese with English abstract) [闻光松, 张涛, 赵峰, 王思 凯, 杨刚, 王妤, 章龙珍 (2016) 基于稳定同位素技术对 长江口主要渔业生物营养级的研究. 生态学杂志, 35, 3131-3136.]

Zhang S, Xie B, Fu XM, Zhang H, Li YK (2016) Trophic level estimation of organisms in landings from Haizhou bay using stable carbon and nitrogen isotope analysis. Marine Environmental Science, 35, 507-511. (in Chinese with English abstract) [张硕, 谢斌, 符小明, 张虎, 李云凯 (2016) 应 用稳定同位素技术对海州湾拖网渔获物营养级的研究. 海洋环境科学, 35, 507-511.]

(责任编委: 李新正 责任编辑: 间文杰) 